Archives of Agriculture and Environmental Science

\title{
A study on organic matter and nitrogen dynamics in wetland paddy soils of Bangladesh
}

\author{
Md. Ashraful Alam, Md. Mizanur Rahman, Mohammed Ziauddin Kamal (iD, Humayun Kabir \\ Shiragi, Most. Shirazum Monira and Momtahina Hasnat \\ Faculty of Graduate Studies, Department of Soil Science, Bangabandhu Sheikh Mujibur Rahman Agricultural University, Gazipur \\ 1706, BANGLADESH \\ *Corresponding author's E-mail: zia_ssc@yahoo.com
}

\section{ARTICLE HISTORY}

Received: 30 January 2019

Revised received: 20 February 2019

Accepted: 22 February 2019

\section{Keywords}

Mineralization

Nutrient dynamics

Organic amendment

Rice

Wetland

\section{ABSTRACT}

The present study was aimed to evaluate the effects of different sources organic matter along with various level nitrogen fertilizations on nutrient dynamics and physicochemical variation of soil at different incubation periods in the research field of department of soil science, BSMRAU. RS, VC, RHB, CD and PM were used @ 2 t C ha ${ }^{-1}$ along with N rates 0, 100 and 150 $\mathrm{kg} \mathrm{ha}^{-1}$ in a factorial randomized complete block design. Combined application of VC and RHB with N100 dose significantly reduces soil bulk density. PM-treated plot resulted the highest amount of TN at 90 DAT, while RHB treated plot at 45 DAT. N fertilized plot showed maximum TN content at 75 DAT with N150 treatment. Significant interaction effects of OM and N on TN content of soil were exhibited at the incubation period 15, 30 and 45 DAT. Different organic amendment showed a dissimilar nutrient release pattern. Significantly higher phosphorus content was detected in VC treated soil while the S content was in the CD-treated soil. The RHB treated plots provide a significantly higher exchangeable $\mathrm{K}$ content in post-harvest soil. The available $\mathrm{P}, \mathrm{S}$ and exchangeable $\mathrm{K}$ contents in post-harvest soil increased positively in all treatments as compared to initial soils. Organic manures and $\mathrm{N}$ fertilization had no significant effect on different chemical properties like soil $\mathrm{pH}, \mathrm{TN}$, available $\mathrm{S}$ and exchangeable $\mathrm{K}$. Significant $P$ enrichment was occurred in organic and $N$ treated soil. Thus, organic and inorganic fertilization had a significant positive influence on the enrichment of physiochemical properties of wetland paddy soil.

(C)2019 Agriculture and Environmental Science Academy

Citation of this article: Alam, M.A., Rahman, M.M., Kamal, M.Z., Shiragi, H.K., Monira, M.S. and Hasnat, M. (2019). A study on organic matter and nitrogen dynamics in wetland paddy soils of Bangladesh. Archives of Agriculture and Environmental Science, 4(1): 1-7, https://dx.doi.org/10.26832/24566632.2019.040101

\section{INTRODUCTION}

Rice (Oryza sativa L.) is the most imperative main foodstuff in the world. Cereal grain rice meets about $1 / 5^{\text {th }}$ of the daily dietary energy demand of half of the world's population (Timmer et al., 2010). In Bangladesh, about $75 \%$ of the total cropped areas and over $80 \%$ of the total irrigated areas are intensified under ricebased cropping pattern (Hossain and Deb, 2003). The demand for production of rice will endure rising in the near future due to shrinkage of cultivable land and over population growth. Farmers are highly interested in increasing cereal grain production by applying excessive amounts of chemical fertilizer. Nonetheless, extensive crop farming degraded the soil fertility and becomes an urgent demand for replenishment with judicious application of manures and fertilizer.

Rice-based cropping pattern in Bangladesh paid little attention on replenishes of degraded soil fertility. Integrated nutrient management along with an organic amendment would provide the congenial crop production ecosystem. The use different organic amendment substantially improved physical and chemical properties of soils (Rahman, 2010). Conversely, the combined application of both organic and inorganic fertilization might be enhancing the carbon sequestration in agricultural soil (Zhu et al., 2015). Nitrogen is the major limiting nutrient for rice production, while its application will further be increased in the next three decades to produce $60 \%$ more rice than today's 
global production (Ladha and Reddy, 2003). Organic matter contributes significant release of soil nitrogen through $\mathrm{N}$ mineralization. However, organic matters content in Bangladesh soil is very poor, ranges from $1-1.5 \%$.

The crop growing process is included a series of complex nutrition translocation mechanisms. Exogenous applications of organic materials can reduce the amounts of chemical fertilizers used and compensate for soil $C$ losses caused by land-use changes (Almagro and Martınez, 2014; Aula et al., 2016; Islam et al., 2016). The nutrient release dynamics of different organic matter play a major role in fertility of natural ecosystems. Organic amendments along with mineral fertilization have a potential for acting as a nutrient reservoir, improving physical properties, thereby maintain agricultural sustainability and enhance crop yield (Zhong et al., 2014). Soil OM plays a key role in nutrient cycling and can help to improve soil structure such as bulk density of soil. Bulk density of a soil is significantly influenced by the amount of organic matter, texture and mineral constituents. Information regarding bulk density is very important for evaluating nutrient dynamics as well as planning of modern farming techniques (Chaudhari et al., 2013; Zhengchao et al., 2013). Soil organic matter is known as a revolving nutrient fund that supplies mainly carbon, nitrogen, phosphorus and sulfur. Decomposition of organic residue plays a major role in global carbon and nitrogen cycling (Manzoni et al., 2008; Ren et al., 2014). The quantity and quality of carbon input, cropping intensity, soil and crop management practices affect carbon and nitrogen dynamics and carbon sequestration at different soil depth (Marland et al., 2004; Tong et al., 2009)

However, in the tropical agriculture system prevailing high temperature accelerate the decomposition of organic input and disrupt nutrient balance. There is great variability in organic matter and its nutrient release dynamics of pudding and dry land agriculture. The nutrient release patterns of soil organic matter are the directly interlinked with the physicochemical environment (aerobic vs. anaerobic, soil structure) and the quality of carbonaceous sources that controlled the regulation of decomposer community (Heal et al., 1997). Several studies reveal that degradation of soil fertility and decline in physical, chemical and biological properties is more prominent in tropical upland production system than wetland rice soils (Sahrawat, 2005). Wetland system might have ameliorative effects on physicochemical fertility and accumulation of organic matter. Scanty empirical data reveal that soil and crop management, enhanced the SOC content in intensive rice-rice cropping pattern (Islam et al., 2016). However, little information is available in organic amended reduced soil system series impact on physicochemical properties motion. At present, it is certain to evaluate the effects of organic and inorganic amendments on soil fertility of degraded wetland soils (Liu et al., 2017). There is a big knowledge gap about the dissimilarity of various organic and inorganic amendments nutrient release dynamics and its effects on physical properties in the wetland paddy soil system. Thus, the present study was lead to investigate effects of different sources organic matter and nitrogen levels singly and in combi- nation on the nutrient dynamics and physicochemical health of wetland paddy soil system.

\section{MATERIALS AND METHODS}

\section{Study site}

The study was conducted in an agricultural field located in the Field Laboratory of the Department of Soil Science, Bangabandhu Sheikh Mujibur Rahman Agricultural University (BSMRAU), Gazipur 1706, Bangladesh. The experimental site is situated at $24^{\circ} 09^{\prime} 22^{\prime \prime} \mathrm{N}$ latitude and $90^{\circ} 25^{\prime} 45^{\prime \prime} \mathrm{E}$ longitudes and $8.2 \mathrm{~m}$ above the sea level. The soil has been classified as Shallow Red Brown Terrace soil in Bangladesh classification and Inceptisols in USDA classification (Brammer, 1996), having silt clay loam soil within $50 \mathrm{~cm}$ from the surface and acidic in nature. The $\mathrm{pH}$ of the initial soil was 6.2 having organic carbon $0.78 \%$, total nitrogen $0.09 \%$, available phosphorus $7.0 \mathrm{mg} \mathrm{kg}$, available sulphur $15.87 \mathrm{mg} \mathrm{kg} \mathrm{kg}^{-1}$ and exchangeable potassium $0.10 \mathrm{cmol}(+) \mathrm{kg}^{-1}$. The climate of the area is sub-tropical, wet and humid.

\section{Experimental design}

The experimental design of the study was in a factorial randomized complete block design with two replications. The factorial experiment included five different organic materials treatments (application of rice straw (RS), poultry manure (PM), vermincompost (VC) and cow-dung (CD) and rice husk biochar (RHB) @ $\left.2 \mathrm{t} \mathrm{C} \mathrm{ha}^{-1}\right)$ and three nitrogen treatments $(0,100$ and $150 \mathrm{~kg} \mathrm{~N}$ $\left.\mathrm{ha}^{-1}\right)$. Each plot had an area of $12 \mathrm{~m}^{2}(4 \mathrm{~m} \times 3 \mathrm{~m})$ and was separated by $30 \mathrm{~cm}$ wide well-structured and polyethylene lined boundary. All of the organic matter except RHB were collected from locally available sources and incorporated with soil during final land preparation. RHB was prepared through the pyrolysis process in an oxygen deficient condition at $350^{\circ} \mathrm{C}$ temperature. The study was conducted in T. Aman season 2016. The moisture, $\mathrm{C}$ and $\mathrm{N}$ contents, $\mathrm{C}: \mathrm{N}$ ratios of the studied organic constituents were presented in Table 1.

One week after proper paddling the field, thirty days old rice seedlings of BINA Dhan 7 were transplanted maintaining a spacing of $20 \mathrm{~cm} \times 20 \mathrm{~cm}$. Soil test based fertilizer doses of $P, K$ and $S$ were applied as triple super phosphate (TSP), muriate of potash (MoP) and gypsum at the rate of 55, 68 and $56 \mathrm{~kg} \mathrm{ha}^{-1}$, respectively (FRG, 2012). The whole amount of TSP, MoP and gypsum was applied during final land preparation. Urea was applied in three equal splits at 15 days after transplanting (DAT), at maximum vegetative stage and panicle initiation stage.

\section{Soil sampling and analysis}

Soil samples from each plot were collected from 0-15 cm depth at different incubation period at 15 days interval $(0,15,30,45$, $60,75,90$ and 105 days) from a T-Aman rice field. Bulk density of the soil also determined at the initial and at crop harvest. Chemical properties of soil and different organic materials were analyzed using standard methods such as soil $\mathrm{pH}$ by glass electrode using a soil and water ratio of 1: 2.5 (Jackson, 1958), 
the total $\mathrm{N}$ content by Micro Kjeldahl method (Black, 1965), available P by Olsen's method (Olsen and Sommers, 1982), sulphur was estimated by turbidimetric method (Chesnin and Yien, 1950) and $\mathrm{K}$ by ammonium acetate extraction method (Barker and Surh, 1982).

\section{Statistical analysis}

Data were statistically analyzed using Statistix version 10.0 statistical software. ANOVA and univariate analyses were performed to test all parameters. Treatment means were separated by least significant difference (LSD). Different graphs were prepared using Microsoft Excel (Office 2007).

Table 1. Physical and chemical properties of organic materials used in the experiment.

\begin{tabular}{lcccc}
\hline \multirow{2}{*}{ Organic materials } & \multicolumn{4}{c}{ Properties of organic materials } \\
\cline { 2 - 5 } & Moisture (\%) & Organic carbon $\left(\mathrm{g} \mathrm{kg}^{-1}\right)$ & Total $\mathbf{~}\left(\mathrm{g} \mathrm{kg}^{-1}\right)$ & C: $\mathbf{N ~ r a t i o ~}$ \\
\hline Rice straw & 8.54 & 362.0 & 4.4 & 82.27 \\
Rice husk biochar & 9.25 & 313.0 & 3.7 & 84.59 \\
Vermicompost & 17.64 & 121.5 & 9.8 & 12.39 \\
Cow dung & 13.76 & 137.5 & 12.2 & 11.27 \\
Poultry manure & 29.69 & 83.7 & 10.9 & 7.67 \\
\hline
\end{tabular}

\section{RESULTS AND DISCUSSION}

\section{Bulk density of wetland soil}

Effects of different organic materials and nitrogen levels on bulk density of soil at initial and after harvest in a wetland paddy system are summarized in Figure 1. Different organic matters significantly lower the bulk density of soil. A significantly higher reduction of bulk density was observed in PM treated plot followed by VC and RHB, compared to the initial one. Bulk density of paddy soil was not influenced by Poultry manure. In contrast, only N100 treated wetland soil showed a slight decline in bulk density. The study clearly indicated that organic matter has a significant effect on soil bulk density as compared with $\mathrm{N}$ fertilizer application. The results explain significant changes in soil quality by addition of different organic and inorganic $\mathrm{N}$ amendments in a wetland system. Both organic matter and inorganic nitrogen had significant effects on bulk density of a wetland paddy soil. There is a strong negative relationship between soil organic amendment and bulk density. The degrees of decomposition of organic matter predominantly synchronize the bulk density and nutrient release pattern in the soil. During the decomposition process of organic matter, microorganism release polysaccharides and raise aggregate stability by enhancing soil particles inter-cohesion and decrease the bulk density (Marland et al., 2004). Among the different organic amendments, RS treated paddy soil showed a significantly higher reduction of bulk density. This result might be due to RS has high a $\mathrm{C}: \mathrm{N}$ ratio and lower mineralization rate with a steady effect. Moreover, the readily decomposable organic amendment has a strong and a transitory effect on the aggregate stability while more stable lignin and cellulose-containing matter have less but consistent effects. Meanwhile, nitrogen treated plot showed an unequal change of bulk density, might be due to nitrogen further enhanced the microbial activity and decomposition rate. Celik et al. (2004; 2010) found alike information that compared to mineral fertilization, different organic amendment reduced the bulk density at $0-15 \mathrm{~cm}$ soil depth.

$\mathrm{N}$ dynamics in soil at different incubation periods

The total-N increased progressively in soils from 15 to 75 DAT and then declined almost in the similar fashion towards 105 days in both organic and inorganic treated soils (Figure 2). The PM treated plot resulted in the highest amount of TN (more than $0.4 \%$ ) at 90 DAT. The RHB treatment showed the highest total nitrogen $(0.35 \%)$ content at 45 DAT. The highest TN content at harvest was observed at 75 DAT with N150 dose. Soil treated with $0 \mathrm{~kg} \mathrm{ha}^{-1} \mathrm{~N}$ contains $0.23 \% \mathrm{TN}$ at $75 \mathrm{DAT}$, while, the soil receiving $100 \mathrm{~kg} \mathrm{ha}^{-1} \mathrm{~N}$ contains $0.25 \% \mathrm{TN}$ at $30 \mathrm{DAT}$, respectively. Apart the physical properties, nitrogen dynamics in soil are one of the most important factors in crop production. With increasing plant age $\mathrm{TN}$ of soil increased as $\mathrm{N}$ dose was applied in splits. Added OM shows a continuous variation of releasing $\mathrm{N}$ in wetland soil might be related with their variations in mineralization potentials. Nutrient dynamics of different organic matter unequivocally variable in different soil and crop management practices, largely due to their $C$ type, microbial breakdown resistance, soil temperature, water content, alternate wetting and drying conditions (Cabrera et al., 2005).

\section{Interaction effects on $\mathrm{N}$ dynamics in soil}

Interaction effects of organic materials and inorganic $\mathrm{N}$ on nitrogen dynamics of soil at different incubation periods are shown in the Table 2. The significant interaction effects of organic materials and $\mathrm{N}$ on TN content of soil samples were observed from 15 days till 45 DAT. At 15 DAT, the significantly higher amounts of TN were found in PM treated plots (0.150\%) along with $100 \mathrm{~kg} \mathrm{ha}^{-1} \mathrm{~N}$. Similar pattern of nutrient release was detected in PM, CD and VC treated soil in combination with 150 $\mathrm{kg} \mathrm{ha}^{-1} \mathrm{~N}$. While RS with $\mathrm{N}_{0}$ dose gave the lowest TN (0.070\%) at 15 DAT incubation periods. At 30 DAT combined application of CD (0.305\%), VC (0.275\%) and $150 \mathrm{~kg} \mathrm{~N} \mathrm{ha}^{-1}$ contributed to the significantly higher amounts of TN in paddy soil. A similar significant increase of TN was found in PM with $0 \mathrm{~kg} \mathrm{~N}^{-1}$ treated plots (0.28\%) at 30DAT, while RHB with $0 \mathrm{~kg} \mathrm{~N} \mathrm{ha}^{-1}$ treated plot gave the lowest TN content (0.16\%). At 45DAT, plot treated with $\mathrm{RHB}$ in combination with $150 \mathrm{~kg} \mathrm{~N}^{-1}$ gave the maximum TN content (0.44\%) whereas plots treated with RS and $100 \mathrm{~kg} \mathrm{~N}$ $\mathrm{ha}^{-1}$ attributed the lowest TN content (0.06\%). At 45 DAT, N release in all organic amendments was higher might be the most active panicle initiation growth stage of study rice BINA Dhan7, which favor higher microbial colonization in rhizospheric soil. 

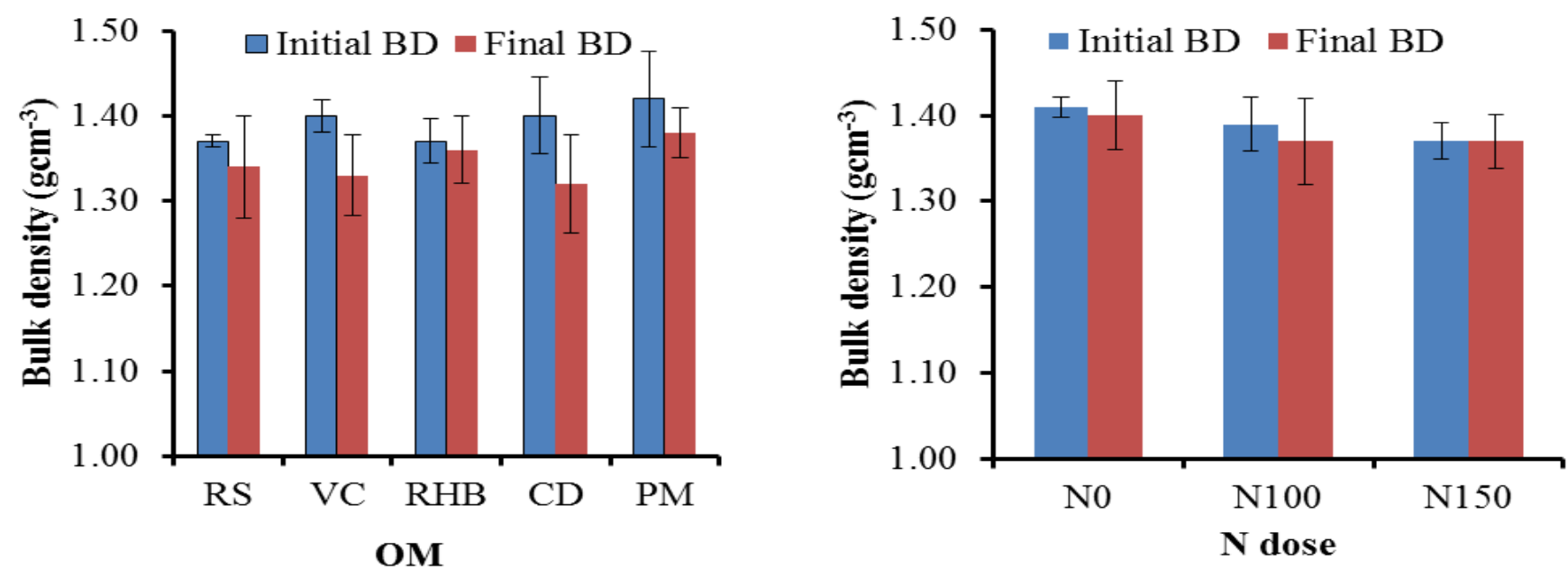

Figure 1. Effect of Organic and different doses of $N$ fertilizer on bulk density of wetland paddy soil; Vertical bar on the column indicates standard error.
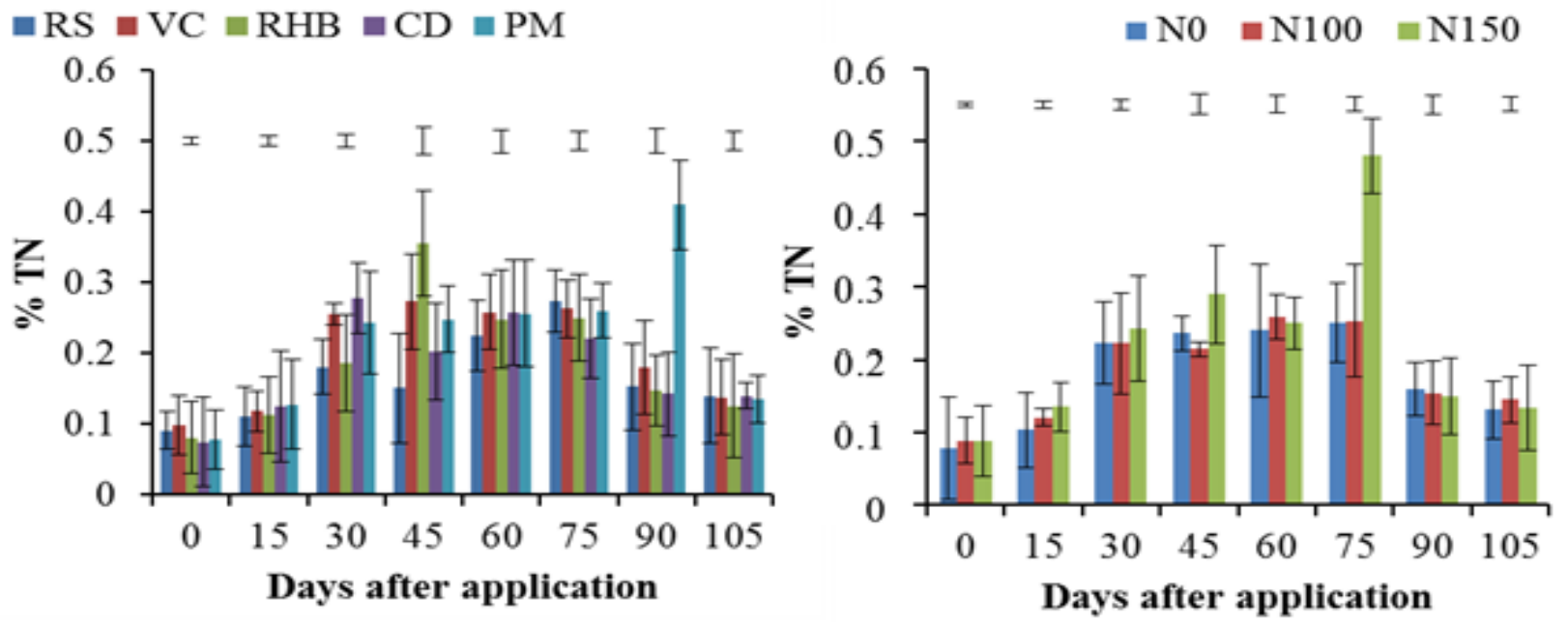

Figure 2. Changes of \%Total nitrogen content of wetland paddy soil at different incubation periods as influenced by different organic matters and $\mathrm{N}$ levels; Vertical bar indicates LSD values, while the bar on the column indicates standard error.

Effect of $\mathrm{OM}$ and $\mathrm{N}$ on chemical properties of post-harvest soil Organic matters and $\mathrm{N}$-levels have made a positive change of different chemical properties of wetland soil, are presented in Table 3. Among the studied chemical properties, a significant enrichment was found in available $P$, while insignificant variation was observed in soil $\mathrm{pH}$ and total nitrogen, exchangeable $\mathrm{K}$ at harvest. Organic materials did not show significant effect on soil total $\mathrm{N}$ at harvest, but the contents was almost double from initial one. Compare to initial soil, OM addition enriches available $\mathrm{P}$ and $\mathrm{S}$ and exchangeable $\mathrm{K}$ contents in post-harvest soil. The highest amount of $P$ in post-harvest soils was found in VC, RHB and PM along with 14.12, 12.83 and $13.26 \mathrm{mg} \mathrm{kg}^{-1}$ soil, respectively. Similarly, $\mathrm{S}$ content in post-harvest soils was significantly higher on the CD $\left(21.83 \mathrm{mg} \mathrm{kg}^{-1}\right)$, and PM $(21.36 \mathrm{mg}$ $\mathrm{kg}^{-1}$ ) treated plots. The significantly higher exchangeable $\mathrm{K}$ content in post-harvest soil was found in RHB treated plots $\left(0.16 \mathrm{c}-\mathrm{mol} \mathrm{kg}^{-1}\right)$, while the lowest one in PM treated plot $(0.12 \mathrm{c}$ $\left.-\mathrm{mol} \mathrm{kg}^{-1}\right)$. Among the studied chemical properties, the significant interaction effect of organic matter and $\mathrm{N}$ level was detected only in $\mathrm{P}$ content at post-harvest soil. Soil microbial communities play a crucial role in bio-geo-chemical processes that is influenced by the addition of different organic and inorganic fertilizers in soils (Jenkinson et al., 1999). Soil pH, TN, available $S$ and exchangeable $\mathrm{K}$ showed no significant response to the interaction effects of $\mathrm{OM}$ and $\mathrm{N}$-levels in residual accumulation of post-harvest soil (Table 3), suggested that enrichment in those attributes were not being easily detected by short-term incorporation. However, slight enhance of $\mathrm{pH}$ in $\mathrm{PM}$ treated soil mainly addition of calcium from poultry manure and its buffering effect (Rahman, 2013). OM decomposition enhances organic acid anions can also increase soil pH due to proton consumption in the decarboxylation process (Hinsinger et al., 2003). OM and $\mathrm{N}$-levels interactions showed the most favorable increase in $\mathrm{P}$ availability in residual soil might be attributed to an acceleration of nutrient release from different manures by the addition of $\mathrm{N}$ through the enhanced mineralization process. The increment in soil $P$ in the acid soil is really good achievement in terms of sustainable management of the most limiting plant nutrient $P$ in the study soil. $\mathrm{N}$ addition did not significantly influence the $\mathrm{N}$ content in residual soil because of its instability in wetted soil through loss process and higher uptake rate. When different organic materials applied they enhanced biological activities in soil, which include high phosphatase activities, microbial biomass content, and dehydrogenase activity. Microbial biomass not only contains a labile pool of nutrients, but also drives the cycling of OM and nutrients in soil (Jenkinson et al., 1999). 
Table 2. Interaction effects of organic materials and nitrogen on $\mathrm{N}$ dynamics in paddy soil at different days after transplanting.

\begin{tabular}{|c|c|c|c|c|}
\hline \multirow{2}{*}{ Incubation period } & \multirow{2}{*}{ Organic materials } & \multicolumn{3}{|c|}{ Nitrogen Fertilizer $\left(\mathrm{kg} \mathrm{ha}^{-1}\right)$} \\
\hline & & 0 & 100 & 150 \\
\hline \multirow{5}{*}{15 DAT } & RS & $0.070 \mathrm{e}$ & 0.080cde & 0.105 bcde \\
\hline & VC & $0.075 \mathrm{de}$ & $0.080 \mathrm{cde}$ & $0.135 a b$ \\
\hline & RHB & 0.110a-e & $0.120 a b c$ & $0.120 a b c$ \\
\hline & $C D$ & $0.120 a b c$ & $0.115 \mathrm{abcd}$ & $0.135 a b$ \\
\hline & PM & $0.110 a-e$ & $0.150 a$ & $0.136 a b$ \\
\hline \multirow{5}{*}{30 DAT } & RS & 0.170gh & $0.185 f g h$ & 0.190fgh \\
\hline & VC & $0.240 \mathrm{~cd}$ & $0.250 b c$ & $0.275 a b$ \\
\hline & RHB & $0.160 h$ & $0.195 \mathrm{fg}$ & $0.205 \mathrm{ef}$ \\
\hline & $C D$ & $0.265 b c$ & $0.265 b c$ & $0.305 a$ \\
\hline & PM & $0.280 \mathrm{ab}$ & $0.215 \mathrm{def}$ & $0.235 \mathrm{def}$ \\
\hline \multirow{5}{*}{45 DAT } & RS & $0.135 \mathrm{~g}$ & $0.060 \mathrm{~h}$ & $0.260 \mathrm{bcde}$ \\
\hline & VC & $0.250 \mathrm{cde}$ & $0.270 \mathrm{bcd}$ & $0.300 b c$ \\
\hline & RHB & $0.320 b$ & $0.305 b c$ & $0.445 a$ \\
\hline & $C D$ & $0.260 \mathrm{bcde}$ & $0.150 f g$ & 0.200 efg \\
\hline & PM & $0.215 \mathrm{def}$ & $0.285 b c$ & $0.245 \mathrm{cde}$ \\
\hline
\end{tabular}

$\mathrm{RS}=$ Rice straw, $\mathrm{VC}=$ Vermicompost, $\mathrm{RHB}=$ Rice husk biochar, $\mathrm{CD}=\mathrm{Cow}$ dung, $\mathrm{PM}=$ Poultry manure; Different letters indicate significant difference among the values.

Table 3. Effect of organic materials and nitrogen on different chemical properties of post-harvest soil.

\begin{tabular}{|c|c|c|c|c|c|c|c|c|c|c|}
\hline \multirow[t]{2}{*}{ Treatments } & \multicolumn{2}{|c|}{ Soil pH } & \multicolumn{2}{|c|}{ Total nitrogen (\%) } & \multicolumn{2}{|c|}{$\begin{array}{c}\text { Available } P \\
\left(\mathrm{mg} \mathrm{kg}^{-1}\right)\end{array}$} & \multicolumn{2}{|c|}{$\begin{array}{c}\text { Available } S \\
\left(\mathrm{mg} \mathrm{kg}^{-1}\right)\end{array}$} & \multicolumn{2}{|c|}{$\begin{array}{c}\text { Exchangeable } \\
\left(\mathrm{c}-\mathrm{mol} \mathrm{kg}^{-1}\right)\end{array}$} \\
\hline & Initial & Final & Initial & Final & Initial & Final & Initial & Final & Initial & Final \\
\hline \multicolumn{11}{|c|}{ Organic matters } \\
\hline RS & 5.17 & 5.44 & 0.090ab & 0.140 & 9.19 & $12.02 b$ & $15.87 b$ & 20.91ab & 0.09 & $0.14 b$ \\
\hline VC & 5.25 & 5.37 & $0.097 a$ & 0.137 & 9.12 & $14.12 \mathrm{a}$ & $15.81 b$ & 19.64ab & 0.10 & $0.15 b$ \\
\hline RHB & 5.27 & 5.38 & $0.082 b c$ & 0.126 & 9.65 & 12.83ab & $15.83 b$ & $19.23 b$ & 0.09 & $0.16 a$ \\
\hline$C D$ & 5.10 & 5.39 & $0.074 c$ & 0.141 & 9.66 & $11.80 \mathrm{~b}$ & $18.18 a$ & $21.83 a$ & 0.10 & $0.15 b$ \\
\hline PM & 5.28 & 5.32 & $0.079 b c$ & 0.137 & 10.65 & 13.26ab & $16.82 \mathrm{ab}$ & 21.37ab & 0.10 & $0.12 c$ \\
\hline S.E. $( \pm)$ & 0.112 & 0.124 & 0.0054 & 0.012 & 0.267 & 0.743 & 0.725 & 1.182 & 0.0051 & 0.0039 \\
\hline \multicolumn{11}{|c|}{ Nitrogen $\left(\mathrm{kg} \mathrm{ha}^{-1}\right)$} \\
\hline 0 & 5.29 & 5.43 & 0.077 & 0.132 & $8.99 b$ & $11.84 b$ & 16.03 & 19.84 & 0.09 & $0.15 a$ \\
\hline 100 & 5.23 & 5.39 & 0.088 & 0.144 & $9.80 a$ & 13.04ab & 17.01 & 21.24 & 0.10 & $0.15 a$ \\
\hline 150 & 5.12 & 5.31 & 0.089 & 0.133 & $10.17 a$ & $13.53 a$ & 16.48 & 20.70 & 0.10 & $0.13 b$ \\
\hline S.E. $( \pm)$ & 0.086 & 0.096 & 0.0042 & 0.009 & 0.207 & 0.575 & 0.562 & 0.916 & 0.0039 & 0.0030 \\
\hline $\mathrm{OM} \times \mathrm{N}$ & ns & ns & ns & ns & ns & $*$ & ns & ns & ns & $*$ \\
\hline CV (\%) & 3.71 & 3.83 & 11.12 & 15.10 & 4.80 & 10.06 & 7.62 & 9.94 & 8.96 & 4.70 \\
\hline
\end{tabular}

RS = Rice straw, $\mathrm{VC}=$ Vermicompost, $\mathrm{RHB}=$ Rice husk biochar, $\mathrm{CD}=$ Cow dung, $\mathrm{PM}=$ Poultry manure; Different letters indicate significant difference among the values.

Conclusion

Addition OM and N Fertilizer have a positive effect on physicochemical properties of wetland paddy soil. Significant reduction of soil bulk density was observed in the organic matter treated plots as compared to $\mathrm{N}$-fertilization. Different sources organic matter showed a variable detected nutrient release pattern. Like, poultry manure treated plot exhibits the highest amount of TN at 90 DAT, while RHB treated plot was shown at 45 DAT. N fertilizer applied plot had shown a maximum amount of TN at 75 DAT with N150 dose. OM and N exhibited maximum influence on the TN content of soil at 15, 30 and 45 DAT. Organic and inorganic amendments positively increased $\mathrm{P}, \mathrm{S}$ and exchangeable $\mathrm{K}$ content in post-harvest soil. Soil $\mathrm{pH}$ did not vary significantly, but increased positively. This study result suggests that the combined addition of organic materials and $\mathrm{N}$ fertilizer could provide a significant improvement of soil health in the wetland paddy system of tropical agriculture.

\section{ACKNOWLEDGEMENT}

Authors impressively acknowledge Krishi Gobeshona Foundation (KGF), Bangladesh, for financing this research activity through CRP -II project.

\section{Conflict of interest}

The authors declare there are no conflicts of interest.

Open Access: This is an open access article distributed under the terms of the Creative Commons Attribution 4.0 License, which permits unrestricted use, distribution, and reproduction in any medium, provided the original author(s) if the sources are credited. 


\section{REFERENCES}

Almagro, M. and Martınez-Mena (2014). Litter decomposition rates of green manure as affected by soil erosion, transport and deposition process, and the implications for the soil carbon balance of a rainfed olive grove under a dry Mediterranean climate. Agriculture, Ecosystems and Environment, 196: 167-177, https://doi.org/10.1016/j.agee.2014.06.027

Aula, L., Macnack, N., Omara, P., Mullock, J. and Raun, W. (2016). Effect of fertilizer nitrogen $(\mathrm{N})$ on soil organic carbon, total $\mathrm{N}$, and soil $\mathrm{pH}$ in long-term continuous winter wheat (Triticum aestivum L.). Communications in Soil Science and Plant Analysis, 47: 863-74 https://doi.org/10.1080/00103624.2016.1147047

Barker, D.E. and Surh, N.H. (1982). Atomic absorption and flame emission spectroscopy. In Methods of soil analysis, Part 2: Chemical and microbiological properties, ed. A. L. Page, R. H. Miller, and D. R. Keeney, Madison, Wisc.: American Society of Agronomy and Soil Science Society of America. pp. 13-26.

Black, C.A. (1965). Total nitrogen. In methods of soil analysis, part 2.Lie Madison Wis. American Society of Agronomy, pp. 1149-1178.

Brammer, H. (1996). The geography of the soils of Bangladesh. The University Press Limited, Dhaka, pp. 132-133.

Cabrera, M.L., Kissel, A.D. and Vigil, M.F. (2005). Nitrogen mineralization from organic residues: research opportunities. Journal of Environmental Quality, 34: 75-79, https://doi.org/10.2134/jeq2005.0075

Celik, I., Gunal, H., Budak, M. and Akpinar, C. (2010). Effects of long-term organic and mineral fertilizers on bulk density and penetration resistance in semi-arid Mediterranean soil conditions. Geoderma, 160:236-243 https://doi.org/10.1016/j.geoderma.2010.09.028

Celik, I., Ortas, I. and Kilic, S. (2004). Effects of compost, mycorrhiza, manure and fertilizer on some physical properties of a Chromoxerert soil. Soil and Tillage Research, 78: 59-67, https://doi.org/10.1016/j.still.2004.02.012

Chaudhari, P.R., Ahire, D.V., Ahire, V.D., Chkravarty, M. and Maity, S. (2013). Soil bulk density as related to soil texture, organic matter content and available total nutrients of Coimbatore soil. International Journal of Scientific Research and Publications, 3: 1-8.

Chesnin, L. and Yien, C.H. (1950). Turbidimetric Determination of Available Sulphates. Soil Science Society of America Journal, 15: 149-151, https://dl.sciencesocieties.org/publications/sssaj/ abstracts/15/C/SS01500C0149

FRG (2012). Fertilizer Recommendation Guide: Bangladesh Agricultural Research Council (BARC), Farmgate, Dhaka, pp. 274.

Heal, O.W., Anderson, J.M. and Swift, M.J. (1997). Plant litter quality and decomposition: An historical overview. In: Cadisch G. \& K. E. Giller (Eds), Driven by Nature: Plant Litter Quality and Decomposition. Centre for Agriculture and Bioscience International, Wallingord, pp. 3-32.

Hinsinger, P., Plassard, C., Tang, C. and Jaillard, B. (2003). Origins of root-mediated $\mathrm{pH}$ changes in the rhizosphere and their responses to environmental constraints: a review. Plant and Soil, 248(1-2): 43-59, https://doi.org/10.1023/A:1022371130939

Hossain, M. and Deb, U.K. (2003). Liberalization of rice sector: Can Bangladesh withstand regional competition? In: PETRRA communication fair 2003 held at hotel Sheraton, Dhaka on Aug 10-11, 2003.

Islam, M.S., Rahman, M.J., Karim, M.R., Kabir, M.A. and Qurashi, T.A. (2016). Agronomic performance and farmers perception on zinc enriched rice BRRI dhan62. International Journal of Agronomy and Agricultural Research, 9: 198-204.

Jackson, M. L. (1958). Soil chemical analysis. Prentice-Hall Inc; Englewood Cliffs.

Jenkinson, D.S., Harris, H.C., Ryan, J., McNeil, A., Pilbeam, C.J. and Coleman, K. (1999). Organic matter turnover in calcareous soil from Syria under a two course cereal rotation. Soil Biology and Biochemistry, 31: 643-648, https://doi.org/10.1016/S0038-0717(98)00157-6

Ladha, J.K. and Reddy, P.M. (2003). Nitrogen fixation in rice systems: state of knowledge and future prospects. Plant and Soil, 252: 151-167, https://doi.org/10.1023/A:1024175307238

Liu, Z., Rong, Q., Zhou, W. and Liang, G. (2017). Effects of inorganic and organic amendment on soil chemical properties, enzyme activities, microbial community and soil quality in yellow clayey soil. PloS One, 12: e0172767, https://doi.org/10.1371/journal.pone.0172767

Manzoni, S., Jackson, R.B., Trofymow, J.A. and Porporato, A. (2008). The global stoichiometry of litter nitrogen mineralization. Science, 321: 684-686, https://doi.org/10.1126/science.1159792

Marland, G., Garten Jr, C.T., Post, W.M. and West, T.O. (2004). Studies on enhancing carbon sequestration in soils. Energy, 29(9-10): 1643-1650 https://doi.org/10.1016/j.energy.2004.03.066

Olsen, S.R. and Sommers, L.E. (1982). Phosphorus. In Methods of soil analysis, part 2: Chemical and microbiological properties, ed. A. L. Page, R. H. Miller, and D. R. Keeney, American Society of Agronomy, Madison, Wisc. pp, 403-430.

Rahman, M.M. (2010). Effect of different organic wastes in tomato (Lycopersicon esculentum Mill) cultivation. Journal of Environmental Science and Natural Resources, 3(1): 247-251.

Rahman, M.M. (2013). Nutrient-use and carbon sequestration efficiencies in soils from different organic wastes in rice and tomato cultivation. Communications in Soil Science and Plant Analysis, $\quad$ 44(9): 1457-1471, https://doi.org/10.1080/00103624.2012.760575

Ren, T., Wang, J., Chen, Q., Zhang, F. and Lu, S. (2014). The effects of manure and nitrogen fertilizer applications on soil organic carbon and nitrogen in a high-input cropping system. PloS One, 9: e97732, https://doi.org/10.1371/journal.pone.0097732 
Sahrawat, K.L. (2005). Fertility and organic matter in submerged rice soils. Current Science, pp. 735-739.

Timmer, C.P., Block, S. and Dawe, D. (2010). Long-run dynamics of rice consumption, 1960-2050. In: Rice in the Global Economy: Strategic research and Policy Issues for Food security, pp. 139-174.

Tong, C., Xiao, H., Tang, G., Wang, H., Huang, T., Xia, H. and Wu, J. (2009). Long-term fertilizer effects on organic carbon and total nitrogen and coupling relationships of $\mathrm{C}$ and $\mathrm{N}$ in paddy soils in subtropical China. Soil and Tillage Research, 106:

8-14, https://doi.org/10.1016/j.still.2009.09.003

Zhengchao, Z., Zhuoting, G., Zhouping, S. and Fuping, Z. (2013). Effects of long-term repeated mineral and organic fertilizer applications on soil organic carbon and total nitrogen in a semi-arid cropland. European Journal of Agronomy, 45:20-26, https://doi.org/10.1016/j.eja.2012.11.002

Zhong, H., Wang, Q., Zhao, X., Du, Q., Zhao, Y., Wang, X., Jiang, C., Zhao, S., Cao, M., Yu, H. and Wang, D. (2014) Effects of Different Nitrogen Applications on Soil Physical, Chemical Properties and Yield in Maize (Zea mays L.). Agricultural Sciences, 5: 1440-1447, https://doi.org/10.4236/as.2014.514155.

Zhu, L.Q., Li, J., Tao, B.R. and Hu, N.J. (2015). Effect of different fertilization modes on soil organic carbon sequestration in paddy fields in south China: A meta-analysis. Ecological Indicators, 53:

144-153, 